\title{
DENTATE GYRUS MOLECULAR LAYER VOLUMETRIC CHANGES IN VALPROIC ACID MOUSE MODEL OF AUTISM SPECTRUM DISORDERS
}

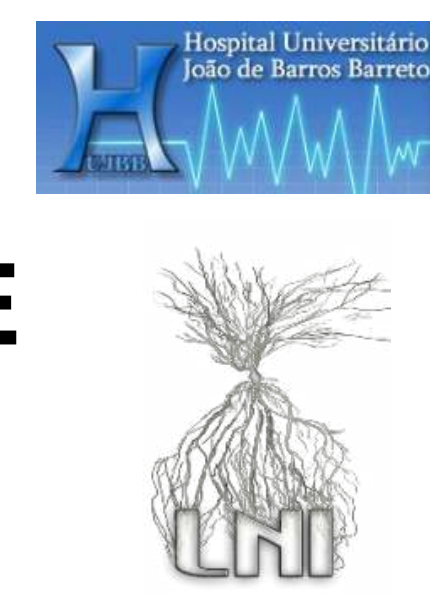

\section{Alinne Lorrany Gomes dos Santos ${ }^{1}$, Luma Cristina Ferreira Guerreiro ${ }^{1}$, Dilza Nazaré Colares de

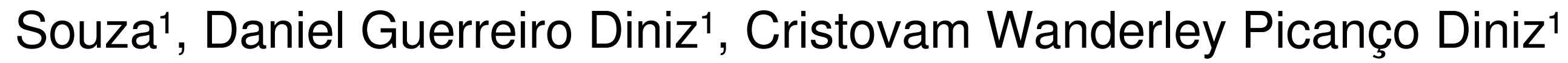

1 Universidade Federal do Pará, Instituto de Ciências Biológicas, Hospital Universitário João de Barros Barreto, Laboratório de Investigações em Neurodegeneração e Infecção, CEP: 66.073005, Guamá, Belém, Pará, Brasil.

To investigate dentate gyrus molecular layer (MolDG) volumetric changes in female mouse model of autism spectrum disorder (ASD) exposed to valproic acid (VPA) in the gestational period. ASD are defined as a group of complex and heterogeneous neurodevelopmental disorders which may include social interaction, motor and cognitive changes. Because we previously reported significant increase of MoIDG microglia number associated with hippocampal-dependent task changes in female VPA mouse model, and because MoIDG is targeted by the entorhinal-to-dentate gyrus perforant pathway, we search for potential volumetric changes of this layer. A single dose of either $600 \mathrm{mg} / \mathrm{kg}$ of diluted VPA in saline, or saline, in equal volumes $(0.2 \mathrm{ml})$ was administered to mouse females on day 12.5 of pregnancy. From $21^{\text {st }}$ postnatal day onwards, females were housed in standard cages, and at 5 months, they were behaviorally tested and sacrificed. Their brains were dissected and anatomical series of sections $(100 \mu m$ thickness) were immunolabelled for IBA-1, a selective marker of microglia. The MoIDG volume was estimated using the Cavalieri estimator.

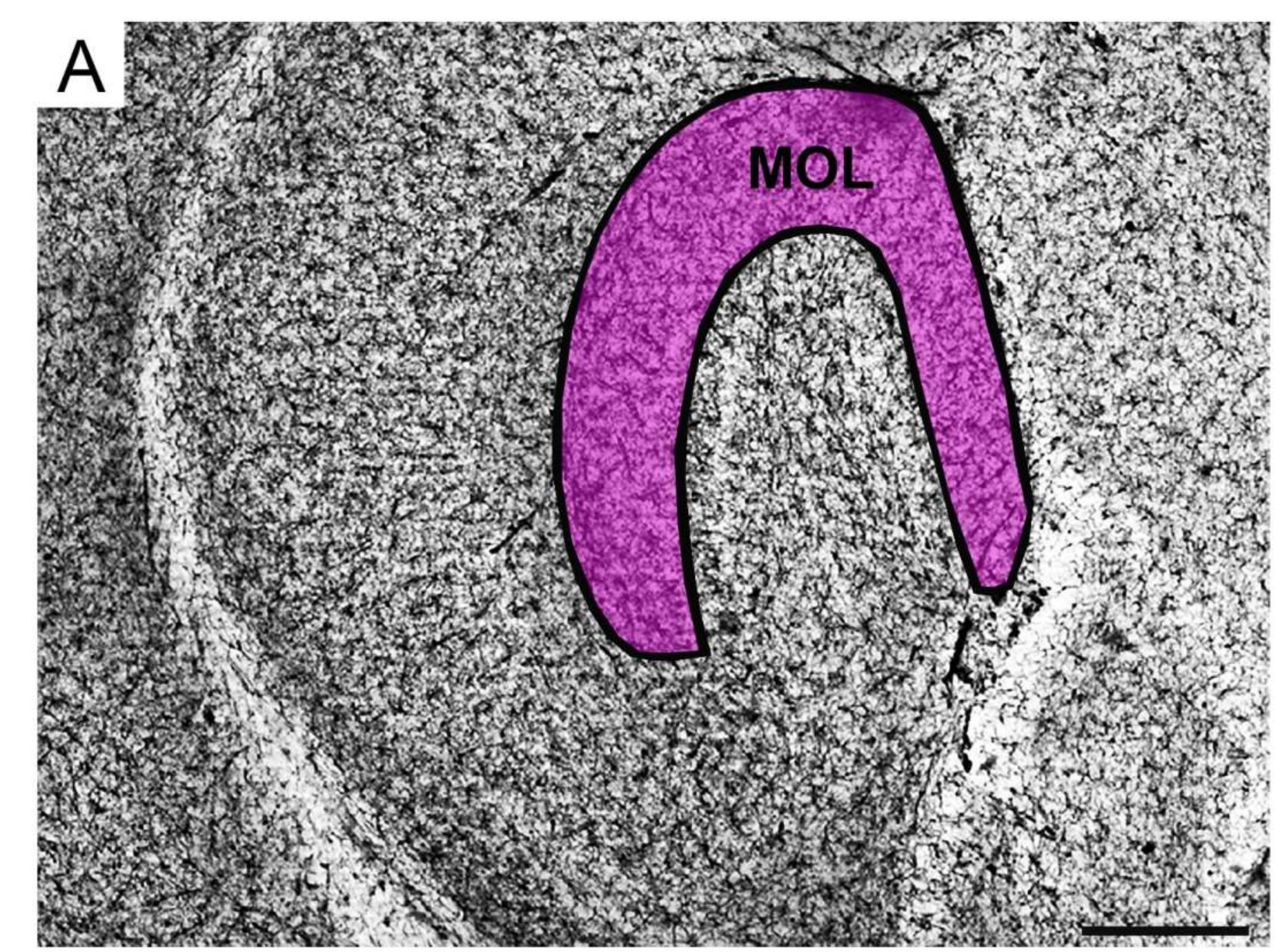

Compared to control animals, we found significant increase in MoIDG volume in the VPA exposed group (two-tailed t test, $0.67 \pm 0.03$ versus $0.80 \pm 0.01 \mathrm{~mm}^{3}, \mathrm{p}=0.0049$, mean \pm standard error). Our findings demonstrate that the increase in the volume of VPA group is associated with significant hippocampal-dependent task changes and with an increase in the number of microglial cells of MolDG in the mice exposed to

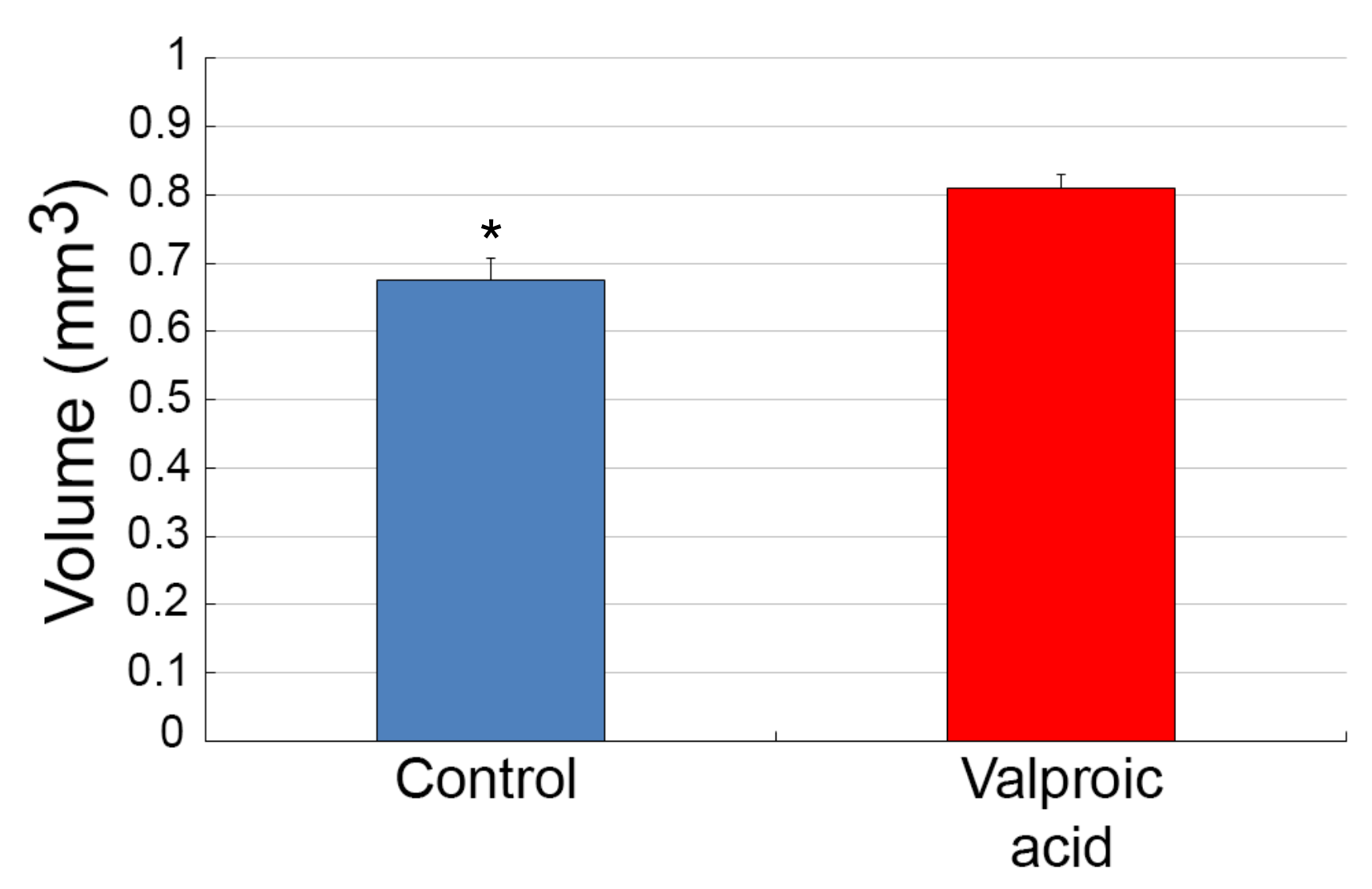

Figura 02 - Volume $\left(\mathrm{mm}^{3}\right)$. Volumetric changes in the molecular layer of the dentate gyrus.

Figure 01 - Molecular layer (MOL) of dentate gyrus and random grid distribution in Cavalieri method. (A) Contour in the molecular layer of the dentate gyrus. (B) Random distribution of the regular grid of test points (white and green). The selected green test points demonstrate the arrangement in the area of interest. Scales bar A: $250 \mu \mathrm{m}$ and B: $180 \mu \mathrm{m}$. 